\title{
Article
}

\section{The UK housing developers' five-star rating: fact or fiction?}

Boothman, James Christopher, Craig, Nigel and Sommerville, James Available at http://clok.uclan.ac.uk/17859/

Boothman, James Christopher ORCID: 0000-0001-7286-6442, Craig, Nigel and Sommerville, James (2018) The UK housing developers' five-star rating: fact or fiction? Journal of Facilities Management, 16 (3). pp. 269-283. ISSN 14725967

It is advisable to refer to the publisher's version if you intend to cite from the work. http://dx.doi.org/10.1108/JFM-10-2016-0039

For more information about UCLan's research in this area go to http://www.uclan.ac.uk/researchgroups/ and search for < name of research Group>.

For information about Research generally at UCLan please go to http://www.uclan.ac.uk/research/

All outputs in CLoK are protected by Intellectual Property Rights law, including Copyright law. Copyright, IPR and Moral Rights for the works on this site are retained by the individual authors and/or other copyright owners. Terms and conditions for use of this material are defined in the policies page.

\section{CLoK}

Central Lancashire online Knowledge www.clok.uclan.ac.uk

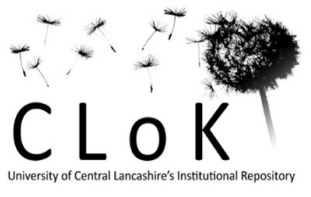




\section{@Emerald Journal of Facilities}

\section{UK HOUSING DEVELOPERS FIVE STAR RATING: FACT OR FICTION?}

\begin{tabular}{|r|l|}
\hline Journal: & Journal of Facilities Management \\
\hline Manuscript ID & JFM-10-2016-0039.R1 \\
\hline Manuscript Type: & Research Paper \\
\hline Keywords: & Customer, Satisfaction, Quality, Housing, Defects, Snagging \\
\hline \multicolumn{3}{c}{} \\
\multicolumn{3}{c}{ SCHOLARONE } \\
\multicolumn{3}{c}{ Manuscripts } \\
\end{tabular}


Purpose - The purpose of the paper is to explore how the data collected by the $\mathrm{HBF} / \mathrm{NHBC}$ surveys is used in practice to improve the service provided to the customers, the transition of any changes into practice and the overall management of the customer satisfaction process by the builder.

Design/methodology/approach - A Qualitative approach to the research was adopted and the findings from the interviews provide an indication of the views from a range of private/speculative house builders relating to the areas of customer satisfaction and the ratings provided through industry based surveys.

Findings - This paper has uncovered the views and opinions of private house builders relating to customer satisfaction and five star ratings. The findings provide evidence that the house building industry is not fully engaged with the HBF five star related concept and that they provide a differing level of service in relation to customer satisfaction.

Research Implications - The research concluded that the customer can be manipulated by the builders in some cases causing a bias in the market; on the whole the customer satisfaction surveys and star rating are simply seen as a marketing tool, used by the builders marketing department as a sign of quality and a way to promote the company.

Practical Implications - This paper is of interest to private house builders and the wider construction industry and will aid their understanding of not only generic customer satisfaction but in particular customer satisfaction in new build housing and quality related ratings/targets applied by industry bodies.

Originality/value - The paper provides an insight to house builders practices by examining the use of the HBF/NHBC survey results and how they are used to manage and improve the service provided to the customer and the results therefore are of value to the end home buyer and the wider house building industry.

Keywords - Customer Satisfaction, Defects, Housing, Quality, Snagging

Paper Type - Research paper.

\section{INTRODUCTION}

For over twenty years the construction industry has seen a continuous outcry from both the government and customers for an improvement in the quality of new homes constructed by the private house-building sector in the UK. As a result of the findings of the Mori/House Builders Federation (HBF) annual surveys completed between 2000 and 2003 and the Barker Review of Housing (2004) the National House Building Council (NHBC) in partnership with the HBF introduced a national survey of house builders, which launched in 2005 as a self-completion survey to the purchasers of new build homes at both eight weeks and nine months after legal completion. The NHBC fund the annual and the HBF undertake this survey on behalf of the NHBC. The members of the HBF (the house builders) are however the same housebuilders that are registered with NHBC and therefore it may be argued that there is no separation between the two organisations.

The Barker review of housing supply (2004) was a wide ranging review of the UK housing supply market examining issues such as defects, snagging, land supply, land banks to name a few and highlighted areas of improvement such as 'service quality' and 'recommending your housebuilder' that the housebuilders must meet over the 
period 2004-2007, and if the sector did not improve in these areas then the Office for Fair Trading (OFT) would be instructed to launch a wide ranging review of housing provision in the UK. The surveys undertaken by the HBF 2004-2007 did indicate some minor improvements in the aforementioned areas but the OFT review did proceed in 2007 and over fifteen separate reports on various sectors of the housing industry were produced and made publicly available but the review did not specifically address the issue of customer satisfaction and therefore an opportunity to address this increasingly important matter was in effect 'lost'.

The Barker review in 2004 laid the foundations for potential change, the OFT investigation in 2007 failed to address the overall concept of quality and customer satisfaction and now in 2016 we have yet another All Party Parliamentary Group (APPG) report on the house building sector and customer complaints which discusses the same issues that Barker and the OFT highlighted but is subjective in nature and therefore it could be argued that little has changed and the issues highlighted long ago still linger.The results of the surveys completed over the past eleven years indicate that there has been a steady improvement across the sector, as commanded by Barker albeit the target of $85 \%$ for service quality was not met until 2010 for the "overall service provided" and has still to be met for the "after sales service" the builders provide to their customer. However the target set of $75 \%$ for the Recommend their house builder was met.

The results of the HBF eight-week survey form the basis for the annual customer satisfaction star rating scheme, which is based on two questions "quality of the home" and "recommendation to a friend" which culminate in the award of a star rating between one and five for the builder. The scheme is only available to HBF members and the participation is optional and it could be argued that any developer/builder that may be awarded a poor rating system could and probably would choose to not be included within the scheme for any year(s). It must further be noted that a number of developers/builders have chosen not to be included and others are excluded, as they are not HBF members. The star rating is awarded on (i) would you recommend your builder to a friend (answer yes or no) and (ii) Taking everything into account, overall how satisfied or dissatisfied you are with the quality of your new home (very satisfied, satisfied, neither, fairly dissatisfied and very dissatisfied). The star rating is applied to question (i) simply with a yes and for (ii) responses that are very satisfied or satisfied. However from 2013 a star rating is awarded for the recommend your builder to a friend only with builders scoring $91 \%$ or higher are five star, $80 \%-89.9 \%$ are a four star, $70 \%-79.9 \%$ a three star and 60\%-69.9\% a two star.

With an increase in demand for new homes and a decrease in both NHBC new home registrations and completions as a result of the economic downturn over the last decade the HBF Customer Satisfaction survey results published include only a snapshot of the data collected within the customer satisfaction survey of new homeowners within the UK eight weeks after legal completion.

This paper seeks to explore how the data collected by the NHBC is used in practice to improve the service provided to the customers, the transition of any changes into practice and the overall management of the customer satisfaction process by the builder. 


\section{THE LITERATURE}

\section{The Concept of Quality and Quality in House Building}

Quality has long been the center of debate and for decades has focused on the improvement of the specific business rather than focusing on the customer or end user of the product. Over this period of time there have been numerous studies and work completed which have been influential in shaping the way we view quality, this includes the work of Shewhart (1931), Feigenbaum (1983), Crosby (1984), Juran (1989), Deming (1986), and Taguchi (1986). The two most influential include the work of Deming and Juran. Deming (1986) proposed that quality can only be defined in terms of customer satisfaction and can be achieved by a business that evolves and continuously strives to improve the service provided to their customers, furthermore he believed that management is responsible for $94 \%$ of all quality issues and stated that 'improving quality will reduce expenses while increasing productivity and market share' (Deming, 1986).

Historically one of the most perplexing issues facing organisations in the construction industry is their inability to become quality focused, which is resulting in a substandard product or service (Love et al 1999). Throughout the last sixteen years following the findings of the Mori surveys (2000-2003), the HBF surveys (2005-to date), Barker (2004) and the OFT (2007), house building organisations have been more focused on managing quality as an attempt to improve their overall performance and competitiveness within the sector and thus has received a considerable amount of attention.

Throughout this period of time numerous other academics and practitioners have researched both defects, snagging, quality and rework within the UK house building industry including Sommerville and McCosh (2006), Sommerville et al (2006), Craig (2007) Sommerville (2008) Auchterlounie (2009) and, Rotimi et al (2014) with the majority of these focusing on defects in terms of numbers created. It is generally acknowledged that the number of defects at the completion or handover stage (completion of the end-product) of a building appears to have a positive or negative influence on the satisfaction of the client or customer, however over the last two decades the construction industry has become obsessed with the attainment of quality through the measurement and use of defects as a proxy. This is demonstrated by Craig et al (2010) whose research analysed over 199,000 defects related to technical and functional quality and established the issues and problems associated with snagging and the house-building sector.

The principles of good quality in the house-building sector are encapsulated in legislation and standards such as the Building Regulations and NHBC Standards and it must be remembered that speculative developers will not respond unless it is imposed by regulations (Watts 2007). Also note that the granting of a local authority habitation certificate or an NHBC completion certificate is not an assurance that the new home is of the required quality levels expected by the home buyer. Local Authority Building control/standards departments also have no control over many of the fixtures and fittings within a new home that are often the cause of many complaints, as these are not controlled or specified within current building standards regulations.

Following a comprehensive review of quality Yi (1993) concluded quality could be measured in two ways, as a product (defects) or as a process (service provided). If quality is considered to be a product, Howard and Sheth (1969) state that "it is the buyers cogitative state of being adequately or inadequately rewarded for the sacrifices 
he has undergone". If it is a process Hunt (1977) suggests that it is an evaluation rendered that the experience was at least as good as it was supposed to be, or it could be an evaluation that the chosen alternative is consistent with prior beliefs with respect to the alternative (Engel and Blackwell 1982, 501) or as Tse and Wilton (1988) suggest 'the consumers response to the evaluation of the perceived discrepancy between expectations and the actual performance of the product'.

Prior to the introduction of quality assurance (ISO9000 \& 9001), the primary measure of quality was the finished product and in the private house building sector the finished product is still the end indicator of overall quality although the housebuilding sector has been inherently slow to adopt the principles of ISO 9000/1 whilst one of the main recommendations of the APPG report (2016) was that housebuilders should' instigate a new quality culture by adopting quality systems to ISO standards'. It is widely acknowledged and understood that good management and organisation leads to a quality product that further leads to customer satisfaction; as Harris and McCaffer (2006) suggest can only be achieved if all the participants directly contribute to achieving the objectives. Forsythe (2015) highlights that the tone of the quality debate has gradually shifted from a predominantly supply-side perspective of quality, to one that increasingly aims to deliver customer value and satisfaction. This is largely because quality is seen as a significant contributor to business success by increasing market share, profits and customer equity (Kotler and Armstrong, 2013). The customer's perception of quality includes more than the satisfaction obtained from the primary product or service, quality is delighting the customer by continuously meeting and improving upon the agreed requirements (Macdonald \& Piggott 1990).

The overall problem is that quality is a subjective issue and positively correlates with the overall customer satisfaction. Craig et al (2010) states that the customer is "perceived simply as a buyer who purchases the final product and as the "customer" they have no control over the finished product or the quality of the product". It must be noted that in the speculative private house building sector the home buyer ordinarily has no or minimal control over the basic specification of the property, the home buyers only input is within the finishes or the options permitted by the house builder albeit this is dependent on the stage of the build when they secured or purchased the property. In the private house building sector it is the house builder who is in effect the client and they therefore build to their own specification requirements which they control. The exception as suggested by Curtis (2011) is the client who is building a bespoke dwelling and is involved with all stages of the process including the design and actual build.

\section{Customer Satisfaction in the House Building Sector}

The purchase of a new home is likely to be the largest single investment an individual, couple or family will make (Stephenson \& Carrick 2006) and the house building industry is facing a more informed client. Stephenson \& Carrick (2006) also suggest that the industry has a poor image, customers are becoming increasingly more aware and savvy and this increased awareness has forced the industry to review the way it views the customer or home buyer. The emergence of the customer as the champion for change has increased the pressure on the construction industry and in particular the private house building sector to provide better quality and better service to satisfy customer needs and expectations (Dulaimi 2004).Customer satisfaction can be seen as a goal or as a measurement tool in the development of construction quality (Karna and Sorvala 2004). 
It is generally acknowledged that the role of satisfaction is well established within the marketing literature and customer satisfaction has become an essential part of performance criteria in the construction sector, particularly house-building. The literature indicates that there is no commonly accepted method of measuring customer satisfaction in the general construction industry (Torbica and Stroh 2000; 2001; Auchterlounie and Hinks 2001) and that satisfaction is a post purchase affect and its measurement is naturally reactive.

The heart of the satisfaction process is the comparison of what is expected with the product or service's performance, which Vavra (1997) describes as the confirmation or disconfirmation process. Customer satisfaction can be determined by either subjective (e.g. customer needs, emotions) or objective factors (e. g. product and service) (Oduro 2012). Numerous researchers have tested the relationship existing between customer expectation, perceived service quality and customers satisfaction and found out that, there is a strong positive correlation (Parasuraman et al, 1985).

The continued media attention on defects and the resulting quality issues in new homes ensures that the issue continues to be a subject of popular debate. Many prospective house buyers believe they are investing in top quality housing developments only to move into their new home and discover it is riddled with faults. The negative manner in which the problem of quality and customer satisfaction has been reported over the years (Kelly, 1998; Dyson, 2004; Barrie, 2006; Linning 2015) is an indication that the house building industry has done little to address 'customer issues' within the new homes arena as customers still feel that the quality standards that have been achieved are low and not to their overall satisfaction. Murray (2005) indicates that some quality initiatives are taken up by house building marketing departments but not on site and moreover, the NHBC and building control inspections do not protect customers. Murray (2005) also states that:

"The result is an industry that should be ashamed of itself. New homes come off the production line with costly defects".

Following two decades of incessant outcry from both the government and customers for an improvement in the quality of new homes in the UK and as a result of the findings of the Mori/HBF surveys (2000-2003) and the Barker Review of housing in 2004 the HBF in partnership with the NHBC introduced a national survey of house builders, which launched in 2005 as a self-completion survey to the purchasers of new build homes at both eight weeks and nine months after legal completion.

The results were first reported in 2006 and consisted of eight questions, a further ten questions were added in 2013 and one in 2014 making a more comprehensive survey. The first eight questions collated data on how satisfied or dissatisfied the home owner was with the service provided during the buying process, completing on time, the condition of the home on the day the purchaser moved in, the standard of finish, the after service provided, problems (i.e. snags, defects) including the number of problems and if they were in line with the expectations of the new home owner. The final two questions were taking everything into account, overall how satisfied or dissatisfied is the homeowner with the quality of their home and would they recommend the builder to a friend which culminate in the developer receiving a star rating (1-5). The statistics published in 2016 included a further question that asked the customer to rate on a scale of one to ten how likely they would be to recommend the builder to a friend (net promoter score, which has three categories Promoter, neutral and detractor) which in the first year (2016) shows that only $47 \%$ of the customers are 
considered to be promoters who would recommend the builder to a friend, the others are neutral or detractors.

Figure 1: Levels of Quality \& Service Provided 2000 - 2016 (adapted from Constructing Excellence 2000, 2001,2003 and the HBF 2006-2016).

The published results of the returned NHBC house builder's eight-week surveys for the "levels of quality" and "service provided" can be seen in figure 1. Initial analysis of the published results indicates that there has been a steady improvement across the sector as commanded by the Barker review 2004. Further analysis taking into account all the four aspects that determine the "quality of a home" see an upward trend in customers reporting defects or snagging, this rising significantly and remaining over $90 \%$, a downward trend in the "quality of the finish", "condition of the new home" and "quality of the new home" which, all significantly reduce until 2006 and then fluctuate for a three year period until a sharp improvement in 2010 which was throughout the years when a significantly lower number of homes were completed and registered with the NHBC. This comes as no surprise as the number of registrations was significantly lower than the 200,700 registrations in 2007 , which further reduced in 2008 to 106,900 and bottomed out in 2009 with 88,100 registrations equating to a $56 \%$ reduction in registrations (see figure 2 ). As the number of completions and registrations increase the overall quality levels are reducing and the overall defects and snagging are increasing.

Figure 2: ONS Homes Started, Completions \& NHBC Registrations 2000 - 2014 (adapted from Constructing Excellence 2000, 2001,2003 and the HBF 2006-2015 \& ONS Statistics 2014).

Barker (2004) called for an improvement in the service quality provided to the customers by the developers and it was expected from the launch date that the overall "service quality" would significantly improve and rise from $65 \%$ to at least $85 \%$ by 2007. The target of $85 \%$ was not met until 2010 for the "overall service provided" and has still to be met for the "after sales service" the builders provide to their customers, which both demonstrate a downward trend as the number of NHBC registration and completions rise. Heath's (2014) findings following "The Barker review" a decade on state that all the three levels highlighted within the Barker review are still to be achieved and the last decade may have been a lost one in terms of the service quality provided to the customers.

The literature reveals that the construction industry and specifically the private house building sector predominately concentrate on defects as an indication of quality when considering customer satisfaction. Albeit the HBF/NHBC customer satisfaction completed over the past decade demonstrate that the house-building sector met some of the improvements commanded by Barker there are other improvements that have still to be met. None of the academic or practice lead research undertaken to date has explored how the data collected by the $\mathrm{HBF} / \mathrm{NHBC}$ is used in practice to improve the service provided to the customers, the transition of any changes into practice or the overall management of the customer satisfaction process by the builder. 


\section{RESEARCH APPROACH}

The research reported in this paper sought to explore how the data collected by the NHBC is used in practice by speculative house builders to (i) improve the service provided to the customers (ii) the transition of any changes into practice resulting from the data received following the satisfaction surveys and (iii) the overall management of the customer satisfaction process by the house builder(s).

To meet the objectives of the study, a qualitative research approach was implemented with semi-structured interviews used to collect data from a range of developers within the North West of England (small, medium and large). The criteria for the size of the house builder is based on the total number of units built per annum with the small $<500$, Medium $>500$ but $<2500$ and the large builder $>2501$ units per year. This approach is supported by Creswell (2009) who states that it is an unfolding model that occurs in a natural setting that enables the researcher to develop a level of detail from high involvement in the actual experiences, allowing the researchers to gather data for the social phenomenon being investigated from the participant's viewpoint (a Phenomenological Study).

To ensure reliability with the data collection the interview sample was selected using 'discriminate sampling' to maximise the chances of collecting relevant data from a small sample. A total of ten developers/house builders (selected from "Buildings" top 25 list of house builders) were identified within the North West (NW) of England who have been awarded a star rating and have been included within the results of all the HBF customer satisfaction surveys published to date (2003-2016). Initially emails were sent to the top ten NW house builders (based on the number of units completed who have been awarded a star rating for all the HBF surveys published 2003-2016) outlining the purpose and background of the study and asking them if they would be willing to participate prior to sending the finally invitation. A total of (3) companies and (8) individuals agreed to participate in the study as displayed in table 1.

\section{Table 1: Interview Participant Profile}

Each participant was invited to take part in a 20 - 30 minute interview (see appendix 1, questions asked at the interview), held at his or her offices between October 2014 and April 2015. The interviews were transcribed then analysed using Nvivo qualitative software, allowing the researcher to arrange the data using a hierarchical tree structure. The central phenomena (customer satisfaction) formed the root of the tree, from which sub-categories or nodes were generated based on a theoretical framework developed from the researchers' previous analysis of the NHBC customer satisfaction surveys. The analysis used open coding to identify the various subcategories associated with the three central themes.

\section{RESULTS}

\section{NHBC Data; How is it used to improve the service provided to the Client?}

The initial area explored during the interviews sought to determine how the information collected in the HBF eight-week customer satisfaction survey is used by the builders to improve their service provide to the customer.

The large and medium size developers indicated that the published results are a good way to benchmark their own company against the competitors; the data revealed that 
the builders only concentrate on the seven areas that make up the quality and the service provided elements of the satisfaction questionnaire (see figure 1). All interviewees agreed that customer satisfaction is unequivocally a necessity of any business albeit it is time consuming and costs a considerable amount of money.

The interviews revealed that the large builder concentrates on maintaining the high satisfaction level for the "recommend the builder" and the "overall quality" to ensure that they retain a high $4 / 5$ star rating. When asked why the interviewee opined;

"A good star rating in the customers eyes is a sign of quality, it sells houses, it's like a hotel rating system the higher the stars rating the better the perceived service and quality of the hotel. Ultimately it's good for marketing the company" (Managing Director A).

When further questioned if they have any data to support the statement they stated;

"we have seen a rise in sales since we have had a four star rating and hope that we will continue to see the same upward trend after we are awarded a five star rating" (Managing Director A).

The medium size builder is very customer focused and unlike the large builder, the company concentrates not on the results of one or two questions, but they consider all the data as valuable for future business development as they are striving to continually improve quality and the service provided to their customers by;

"building on their past results and developments to improve the next and concentrate on managing the customers' expectations rather than relying on the overall satisfaction of the customer, based on the results of the eight week HBF survey" (Managing Director D).

The small builder disregards the results of the HBF satisfaction surveys considering them as irrelevant stating;

"To us a true measure of the level of a customer's satisfaction is repeat business or a good relationship throughout the building process, providing a home that meets the needs and expectations of the customer. A good reputation is more important to us as a small family business and it sells houses" (Managing Director G).

\section{Changes into Practice}

The next area reconnoitred through the interviews sought to establish how the builders implement any changes highlighted by their results of the HBF customer satisfaction surveys to improve either the quality of the finished home, the service provided and or the overall satisfaction of their customers. Once again the interviews revealed that both the large and medium builders implement changes to improve the results.

The managing directors and contract managers agree that they restrict the extras (additional items not included within the standard building specification for the specific house type) allowed depending on the stage of the build for each property. They have a consensus of opinion that the extras permitted within the property is dependent on the base specification of the property (which the house builder controls) as some levels of finish don't allow certain extras, for example the entry level property has a minimal number of allowable extras;

"if a bath is from the budget range, of a poor quality it flexes so much that we only fit a shower curtain and therefore do not offer a shower screen upgrade due to the number of reports of it leaking as we cannot get a seal between the bath and the 
shower screen, therefore we no longer offer this as an option which improves the overall satisfaction of the customer" (Contracts Manager, Large Builder B).

\section{Managing the Customer Satisfaction Process}

The final area explored during the interviews revealed that the large developer is more customer focussed and commercially aware of the importance of customer satisfaction and the future new homes sales, therefore are very proactive in contacting the client a number of times over the first two - three weeks after the move-in period through their dedicated customer services department.

"our customer care team contact the client seven and fourteen days after legal completion to see if they are experiencing any problems or issue since they moved in and also enquire if the site manager has completed the minor issues and scheduled for the others outstanding issues or defects to be completed. At six weeks they are contacted again and the process is repeated if required" (Managing Director A).

The regional office for Managing Director A compete with the other regional offices in the UK within their company in relation to the satisfaction level achieved (based on the results of the independent survey completed by a third party) who contact the customers by telephone to carry out a satisfaction survey approximately six weeks after legal completion. The results are immediately sent to the builder, any outstanding issues are highlighted, the builder receives a score (between one and ten), to indicate if they are a promoter $(>7)$ or a detractor $(<7)$ if a detractor or any issues are outstanding the builder will contact the home owner to resolve any outstanding defects or issues prior to receipt of the eight week HBF survey.

The medium sized developer is not proactive in the follow up service they provide and they are much more reliant on site based staff to rectify any customer issues that have arisen. They employ the same external company to complete a satisfaction survey providing them with a similar data set as the large builder, which acts as a trigger point to complete any outstanding issues or defects if not already complete however;

"when eight weeks after legal completion has passed we are not proactive in resolving any outstanding issues, as it's too late to affect the survey results so we concentrate on the properties that still may receive the survey" (Managing Director D).

The interviews further revealed that both the large and medium builders offer a range of incentives to their staff if they (i) retain or improve on the HBF star rating, (ii) the overall HBF results relating to the customer satisfaction improve on the previous year or (iii) the development is completed ahead of programme. The builders urge the customer facing staff to actively encourage customers to complete the HBF satisfaction survey, canvassing the customer in relation to the importance of a favourable outcome for the "recommend the builder to a friend" question.

\section{Discussion}

The lack of detailed research in the area of quality in new build homes and in particular the role of the $\mathrm{HBF} / \mathrm{NHBC}$ surveys somewhat prohibits us from discussing the findings of this research directly with prior work/s. However, previous research in associated areas has identified the major sources and causes of quality and whilst this work is centred on new housing, a full-scale industry wide research effort is required to delve into the wider issues and arrive at a broadly meaningful set of conclusions.

New homes of very poor quality are being repeatedly handed over to the customer which cause the customer to be dissatisfied with overall quality although in some 
respects this does not seem to greatly affect the 'ratings' received by the housebuilders through the HBF/NHBC survey results. There continues to be a gap between buyer expectations and what the industry delivers and yet there is scant evidence of effort being applied within the industry to bridge this gap. The various reports produced over the last 30 years which have flagged the quality issue as an area of concern seem to have fallen on deaf ears and leaves the construction industry in general open for comments and investigations from others.

Quality initiatives (surveys, reports, five star ratings) within the industry have been promulgated and implemented under a number of guises and yet the end-product - the new home is still sadly lacking in quality and end home buyers are still not fully satisfied with their new home. If the house building industry is able to produce an improved way of monitoring quality and customer satisfaction then hopefully overall satisfaction with quality can be improved but instead housebuilders rely on 'marketing' initiatives such as five star ratings which could be argued still fail to deliver the ultimate end-product i.e. the new home. Indeed this research has highlighted the differing approaches to customer satisfaction across a range of house builders and also how these builders perceive the 'ratings' given to them by the survey results of the HBF/NHBC surveys. It could be argued that focusing on generic quality issues and placing less emphasis on 'five-star' ratings would improve customer satisfaction which would in turn take care of and improve the ratings system although the evidence to support this is sadly lacking. At present however the ratings system is simply seen as a marketing tool to promote the house building organisation and it could be argued that is of little actual relevance to the end customer.

\section{CONCLUSIONS}

This paper sought to explore how the data collected by the NHBC is used in practice to (i) improve the service provided to the customers, (ii) the transition of any changes into practice and (iii) the overall management of the customer satisfaction process by the builder. The literature revealed that the HBF customer satisfaction survey results demonstrate that the house-building sector has met some of the improvements commanded by Barker but still need to meet the others. The results published by the HBF neglect to look at the long-term satisfaction of the customer, due to the published statistics and figures being solely based on the eight week satisfaction survey.

The analysis of the exploratory data provided through the interviews with the developers revealed a gap between the published statistics and current practice and further suggest the surveys are unlikely to reflect the true experiences and opinions of the customer. It furthermore suggests that as a result of the in-house survey instructed by the developers can influence the results of the HBF eight-week customer satisfaction survey as the customers are contacted at key stages prior to the receipt of the eight week survey, thus causing a bias in the market. The large and medium builders appear to concentrate on the on the customer satisfaction surveys and particularly the star rating which is seen simply as a marketing tool, used by the builders marketing department as a sign of quality and a way to promote the company.

The star rating awarded to the builder is based on two questions (until 2013) and one subsequently is calculated using a limited number of the actual completed unit/s by the particular builder in the any year awarded. The question introduced in the 2014 which rates on a scale of 1-10 and asks how likely would you be to recommend your builder to a friend, when considering the results in the first published year its reported 
that only $47 \%$ are home owners are considered as promoters and $53 \%$ either detractors or neutral, which does not reflect the figure of $85 \%$ reported for the "recommend your builder to a friend" question for the same year (2015) published in 2016. For the star rating to be more realistic rating a larger number of returned surveys should be included within the calculation of this award and it should also include a wider range of questions to include all the questions (figure 2) that make up quality and service provided aspects of the HBF eight week questionnaire. This would provide a more robust system for awarding the star rating which in turn would improve the over quality and the service provided to the customer as commanded by Barker and would also be a better reflection of quality and a guide for future home buyers in the UK.

After reviewing the literature, it has been determined that most research surrounding the concept of quality within the new build housing sector has been inherently biased towards the identification of defects as an indicator of quality. This research project has begun to address this imbalance and focus specifically on the customer satisfaction issue and demonstrates how the house builders view the ratings system applied by the HBF/NHBC surveys and is therefore of particular relevance to house builders and home buyers alike. The approach to the research also provides the industry with a solid opportunity to concentrate upon the most important member of the house building process 'the customer'. This research has contributed towards the body of knowledge not only by enriching the existing knowledge bank within customer satisfaction discipline but also by determining the key issues and areas of quality that need to be better understood. The house builders of course could be asked to shoulder some of the blame for this lack of quality focus but the responsibility may better sit on the shoulders of the numerous buyers who have accepted products with lower than anticipated quality standards.

\section{REFERENCES}

APPG, (2016) All Part Parliamentary Group for excellence in the Built Environment, More Homes Fewer Complaints, July 2016, House of Commons, London

Auchterlounie, T (2009),"Recurring quality issues in the UK private house building industry", Structural Survey, 27 (3) pp. $241-251$.

Auchterlounie, A. and Hinks, J. (2001) Assessing customer criteria for quality in new housing, first post-graduate research Conference University of Salford, Manchester.

Barker, K. (2004) Review of Housing Supply, Her Majesty's Stationery Office, Norwich.

Barrie, J. (2006) House of Horrors, Daily Record and Sunday Mail, Glasgow.

Curtis, M.D. (2011), New House Owners' Satisfaction Survey 2011, Building Research Levy, Wellington.

Craig, N. (2007), "The prevailing trend of defects and snagging in new homes in the UK", $\mathrm{PhD}$ thesis, Caledonia University Glasgow, Glasgow.

Craig, N. Sommerville, J. and Auchterlounie, A. (2010) "Customer satisfaction and snagging in the UK private house building sector." Proc., 26th Annual ARCOM Conf. Association of Researchers in Construction Management, Leeds, UK, 2010.

Creswell, J W (2009) "Research Design: Qualitative, quantitative and mixed method approaches" 3ed. London: Sage Publications.

Crosby, P B. (1984). Quality without Tears. USA: McGraw Hill.

Deming, W, E. (1986) Out of the Crisis. Cambridge, England: MIT/CAES Press. 
Dulaimi, M, F. (2004) The challenge of customer orientation in the construction industry. Construction innovation, Edward Arnold.

Dyson, R. (2004) These houses are defective. I should know I built them, Evening Standard, London.

Engel, J.F. and Blackwell, R.D. (1982) Consumer behavior. Minnesota, Dryden Press.

Feigenbaum, A.V. (1983). Total Quality Control. 3rd Ed. New York: McGraw Hill.

Forsythe, P. (2015) Monitoring Customer Perceived Service Quality and Satisfaction during the Construction Process, Construction Economics and Building, 15(1), 19-42.

Harris, F \& McCaffer, R. (2006) Modern Construction Management. 6th Ed. London: Blackwell Scientific Publications.

HBF, (2006-16) New home customer satisfaction, Home Builders Federation, London.

Heath, (2014) Barker Review a decade on, Home Builders Federation, London.

Housing Forum. (2000-2003) National Customer Satisfaction Survey, Constructing Excellence, London.

Howard, J. A., Sheth, J. N. (1969). The Theory of Buyer Behaviour. London: Wiley.

Hunt, H. K (1977), "CS/D -- Overview and Future Research Directions," in Conceptualization and Measurement of Consumer Satisfaction and Dissatisfaction, H. Keith Hunt, ed., Cambridge, MA: Marketing Science Institute, 455-488.

Juran, J M. (1989) On Leadership for Quality New York: Jossey Bass.

Karna, S. and Sorvala, V. (2004) Factor-specific approach to customer satisfaction with construction, CIB W55/65CIB, Rome.

Kelly, R. (1998) Complaints rise over defects in new houses, Times Newspapers Limited, London.

Kotler, P. and Armstrong, G. (2013). Principles of Marketing. 15th Ed. Pearson.

Linning, S. (2015) The new house from hell! Cracks in the walls, no loft insulation and a $£ 3,000$ kitchen worktop that doesn't fit: Homeowner finds 140 problems with his brand new £580,000 house, Mail Online, London

Love, P. E. D, Mandal, L, P: Li, H. (1999): Determining the causal structure of rework influences in construction, Construction Management and Economics, 17:4, 505-517.

Macdonald, J. and Piggott, J. (1990) Global Quality: the new management culture, London, Mercury Books.

Murray, M. (2005) Housebuilders just don't care, CIOB, Ascot.

Oduro, R. (2012) Factors that determine customer satisfaction level in banking institutions: Evidence from Ghanaian banking industry, Asian Journal of Business and Management Sciences, Vol 2 No 7 pp 01-13.

Parasuraman, A., Zeithaml, V.A. and Berry, L.L., (1985). A conceptual model of service quality and its implications for future research. The Journal of Marketing, pp.41-50.

Rotimi, F.E., Tookey,J.E. and Rotimi, J.O.B (2014),"Home owners and developers relationships: exploring the cordiality factor", Structural Survey, Vol. 33 Iss 3 pp. 278 -292 .

Sommerville, J. (2008), "Homebuilding market study", Office of Fair Trading.

Sommerville, J., Craig, N. and Ambler, V. (2006), "Functional and technical quality in new homes in the UK: the snagging problem", paper presented at the COBRA RICS Annual Conference, 7-8 September, University College, London. 
Sommerville, J. and McCosh, J. (2006) Defects in new homes: an analysis of data on 1696 new UK houses, Journal of Structural Survey, vol. 24, no. 1, pp. 6-21.

Stephenson, P and Carrick, C.J. (2006) Select and accept a new build home: buyers' experiences, expectations and attitudes. In: Smyth, H. (eds) Royal Institution of Chartered Surveyors Annual COBRA Conference. London: RICS.

Shewhart, W.A., (1931). Economic control of quality of manufactured product. 509. ASQ Quality Press.

Taguchi, G., (1986). Introduction to Quality Engineering. Tokyo: Asian Productivity Organisation.

Torbica, Z.M. and Stroh, R.C. (2000) HOMBSAT - An instrument for measuring home buyer satisfaction, Quality Management Journal, vol. 7, no. 4, pp. 32-44.

Tse, D. K, and Wilton, P. C. (1988), "Models of Consumer Satisfaction Formation: An Extension," Journal of Marketing Research, 25 (May), 204-12.

Vavra, T.G. (1997) Improving your measurement of customer satisfaction: A guide to creating, conducting, analyzing, and reporting customer satisfaction measurement programs. Milwaukee, WI: Society of Automotive Engineers,U.S.

Watts, G. (2007). The Callcut Review of House building Delivery. London: Construction Industry Council.

Yi, Y. (1991). A critical review of consumer satisfaction, in Zeithaml, V.A. (1989). Review of marketing 1989. Chicago: American Marketing Organisation. 
Figure 1: Levels of Quality \& Service Provided 2000 - 2016 (adapted from Constructing Excellence 2000, 2001,2003 and the HBF 2006-2016).

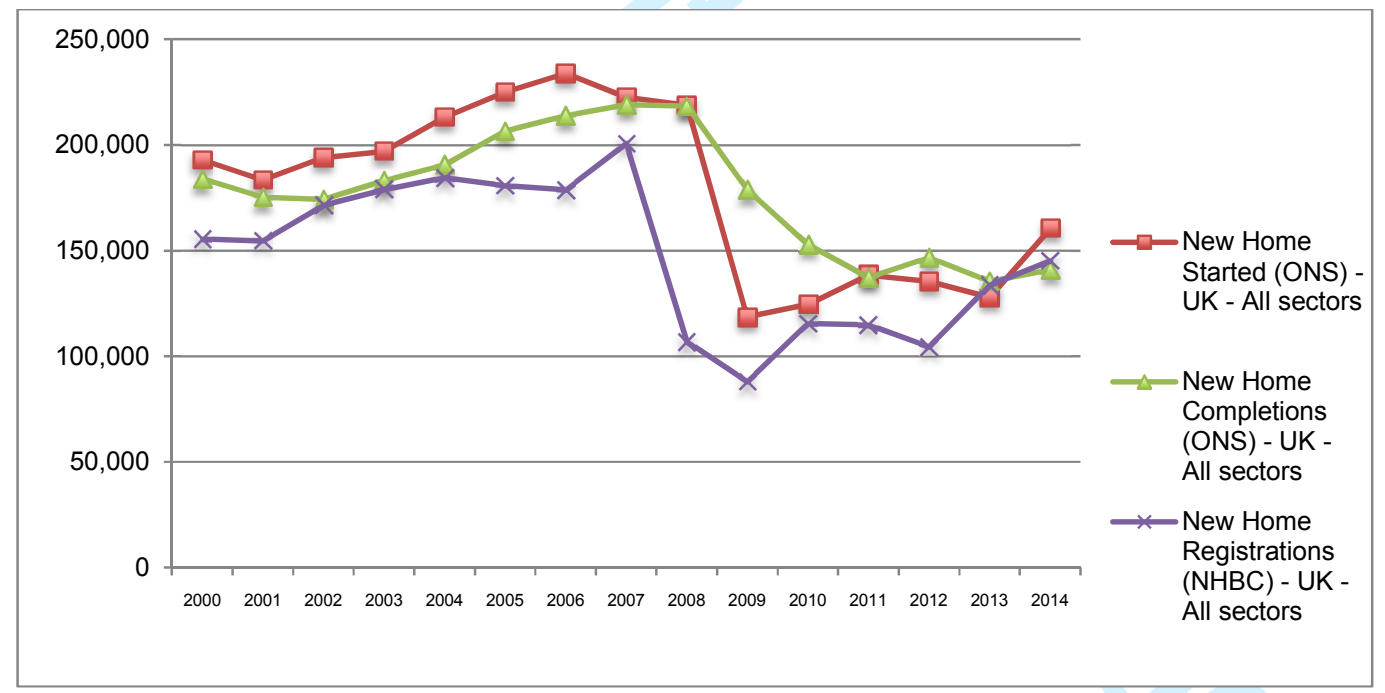

Figure 2: ONS Homes Started, Completions \& NHBC Registrations 2000 - 2014 (adapted from Constructing Excellence 2000, 2001,2003 and the HBF 2006-2015 \& ONS Statistics 2014). 


\begin{tabular}{lll}
\hline Respondent & Role & Type of organisation \\
\hline A & Managing Director & Large Developer \\
B & Contracts Manager & Large Developer \\
C & Site Manager & Large Developer \\
D & Managing Director & Medium Developer \\
E & Contracts Manager & Medium Developer \\
F & Site Manager & Medium Developer \\
G & Managing Director & Small Developer \\
H & Site Manager & Small Developer \\
\hline
\end{tabular}




\section{Semi Structured Interview Questions/Discussion Topics}

\section{Background Information}

- Current Job Role \& Previous Roles at the company

- Number of years with the company

- Previous experience and past roles and companies worked for etc.

\section{Customer Satisfaction}

- How does your company manage the customer satisfaction process?

- How do you use the HBF/NHBC eight-week survey results to improve customer satisfaction?

- Is the company proactive in relation to improving the customer's satisfaction pre occupation?

If so how?

- Explain the process operates and what is involved

o How could this be improved for both the company and the customer?

- Is the company proactive to improve the customer's satisfaction post occupation?

- If so how

- Explain the process operates and what is involved

- How could this be improved for both the company and the customer?

\section{Service Provided to the Homebuyer}

- Do you use the HBF/NHBC eight-week survey results used to improve the service you provide to the customer?

- How are the HBF/NHBC nine-month survey results used to improve the service you provide to the customer?

\section{Change Implementation}

- How are the required changes implemented following the results received from the HBF/NHBC survey results?

\section{Aftersales \& Customer Care}

- Is the after sales In-house or Contracted out

- In your opinion is the aftersales service you provide effective for the customer? 
- How does the aftersales process operate?

- Is the company proactive until all the issues or defects are complete, or is this dependent on specific timescales after legal completion or occupation of the property?

- Does the company actively encourage the customer to complete the NHBC 8 week questionnaire?

How does this operate?

- Are any incentives offered for the completion of a positive answer to any of the questions included within the questionnaire? 